\title{
Mutant GNAQ promotes cell viability and migration of uveal melanoma cells through the activation of Notch signaling
}

\author{
HONGLEI LIU ${ }^{1}$, CHUNLING LEI $^{1}$, KEQIN LONG ${ }^{1}$, XINGUANG YANG ${ }^{1}$, \\ ZHAOLIANG ZHU ${ }^{1}$, LIHUA ZHANG ${ }^{2}$ and $\mathrm{JUN} \mathrm{LIU}^{2}$ \\ ${ }^{1}$ Department of Ophthalmology, Xi'an No. 4 Hospital, Xi'an, Shaanxi 710004; \\ ${ }^{2}$ Department of Gerontology, Tangdu Hospital, Xi'an, Shaanxi 710038, P.R. China
}

Received December 11, 2014; Accepted April 3, 2015

DOI: $10.3892 /$ or.2015.3949

\begin{abstract}
The occurrence of guanine nucleotide binding protein (G protein), q polypeptide (GNAQ) mutations has been found to be high in the majority of uveal melanomas. However, the underlying molecular mechanism of GNAQ mutations in modulating uveal melanoma is poorly understood. The aim of the present study was to investigate the role and underlying mechanism of mutant GNAQ in the regulation of cell viability and migration of uveal melanoma cells. Uveal melanoma cells containing mutant GNAQ were transfected with scrambled or GNAQ small-interfering RNA. Compared with the control, GNAQ knockdown markedly inhibited cell viability and migration. However, tumor cells without GNAQ mutations exhibited enhanced viability and migration following transfection with HA-GaqQL. Additionally, GNAQ knockdown significantly downregulated the expression of Jag-1 (Notch ligand), Notch intracellular domain and Hes-1 (Notch target gene) in uveal melanoma cells. Conversely, the GNAQ overexpression promoted their expression. Cell viability and migration induced by GNAQ was significantly inhibited following treatment with $5 \mu \mathrm{mol} / 1$ MRK003, a Notch signaling inhibitor. Furthermore, the transfection of human influenza hemagglutinin A epitope (HA)-GaqQL into tumor cells caused Yes-associated protein (YAP) dephosphorylation and nuclear translocation, which stimulated the expression of Jag-1 and Hes-1. Positive correlations were observed between the GNAQ and Jag-1 mRNA levels and between the GNAQ and Hes-1 mRNA levels. However, no positive correlation was observed between the GNAQ and YAP mRNA levels. The results suggested that GNAQ mutation induced viability and migration of uveal melanoma cells via Notch signaling activation, which is mediated by YAP dephosphorylation and nuclear translocation.
\end{abstract}

Correspondence to: Dr Jun Liu, Department of Gerontology, Tangdu Hospital, 1 Xin Si Road, Baqiao, Xi'an, Shaanxi 710038, P.R. China E-mail: junliutd@163.com

Key words: GNAQ, uveal melanoma, Notch, viability, Yes-associated protein, migration

\section{Introduction}

Uveal melanoma is the most common primary intraocular tumor in adults, and has a reported annual incidence of $6.3 / \mathrm{million}$ among Caucasians, 0.9 among Hispanics and 0.24 among individuals of African descent (1). The incidence is much lower within Asian populations although uveal melanoma may occur earlier $(2,3)$. It was previously reported that $20 \%$ of uveal melanomas occurred in patients between 19 and 30 years of age (4). The 5-year survival rate of patients with uveal melanoma has remained at $81.6 \%$ over the past three decades regardless of the development of local eye treatment (5). Therefore, it is critical to identify patients at high risk of metastatic disease, which may be useful in selecting patients that may benefit from adjuvant treatment (6). The organs to which uveal melanoma most commonly metastasize are the liver (95\%), lungs (24\%), bone $(16 \%)$ and skin $(11 \%)$. These metastases may significantly influence the patient survival rate. Patients with liver metastases have a median survival rate of 4-6 months and a 1-year survival rate of $\sim 10-15 \%$. By contrast, patients with no liver metastases have a median survival rate of $\sim 19-28$ months and a 1-year survival rate of $\sim 76 \%$ (7).

GNAQ and GNA11 mutants (encoding Gaq and Ga11, respectively) occur in $\sim 5 \%$ of all tumors and contribute to cell viability and migration (8). Daniels et al (9) demonstrated that mutations in GNAQ (47\%) or GNA11 (44\%) were detected in the majority $(91 \%)$ of large uveal melanomas. However, these oncogenic mutations have rarely been identified in other types of cancer. $G$ protein $\alpha$ subunits may transduce external signals to intracellular signaling pathways, which activate the phospholipase $\mathrm{C}$ and mitogen-activated protein kinase pathways, promoting proliferation and the cell survival rate of melanoma cell lines (10). Constitutively active GNAQ and GNA11 mutants may activate the extracellular signal-regulated kinase (ERK) pathway, and knockdown of mutant GNAQ in uveal melanoma cells may lead to mitogen-activated protein kinase inhibition, cell growth reduction and apoptosis induction (11). However, the effect of mutant GNAQ on uveal melanomas has not been completely elucidated.

Four Notch receptors (Notch1-4) are found in mammals and play an essential role in tumorigenesis. Two ligand families, Jagged (Jag-1 and Jag-2) and $\delta$-like ligand, are required for the activation of canonical Notch signaling (12). Binding 
of these ligands to the Notch receptor results in its cleavage by the tumor necrosis factor- $\alpha$-converting enzyme (13). The final cleavage event, which is induced by the $\gamma$-secretase complex, releases the Notch intracellular domain (NICD), stimulates nuclear translocation and modifies the gene expression (14). The best studied genes that are modified by NICD are the Drosophila proteins hairy and enhancer of split, homologs to human hairy and enhancer of split (Hes), and hairy and enhancer of split related with YRPW motif (Hey) families (15). Activation of Notch1 has been reported to promote cell growth and tumor invasion in human cutaneous melanoma (16). Notch1 activation also induces a transformed cell phenotype in cutaneous melanocytes in vitro (17). The role of Notch signaling has been examined in uveal melanoma and was found to promote proliferation, clonogenic growth and invasion in tumor cells (18). Nevertheless, to the best of our knowledge, few studies have reported the interaction between Notch signaling and mutant GNAQ in uveal melanoma.

The present study revealed that mutant GNAQ promotes uveal melanoma cell viability and migration through the activation of Notch signaling. Inhibition of Notch by MRK003 resulted in decreased cell viability and migration. Furthermore, Yes-associated protein (YAP) dephosphorylation and translocation were stimulated by GNAQ and mediated Notch signaling activation in uveal melanoma cells. Thus, we found an association between the GNAQ mutation and Notch signaling, which may facilitate the identification of therapies to treat uveal melanoma.

\section{Materials and methods}

Cell culture and tumor tissues. Five cell lines, including 92.1, OMM2.2, OMM2.5, Mel285 and Mel290 (provided by Dr Martine Jager of Leiden University, The Netherlands), were cultured in RPMI-1640 medium supplemented with $10 \%$ fetal calf serum (FCS), $2.5 \mu \mathrm{g} / \mathrm{ml}$ fungizone ${ }^{\circledR} /$ amphotericin $\mathrm{B}, 50 \mu \mathrm{g} / \mathrm{ml}$ gentamicin and $2 \mathrm{mM}$ L-glutamine (Gibco, Invitrogen, Carlsbad, CA, USA) as previously described (19). The cells were cultured at $37^{\circ} \mathrm{C}$ in a humidified air/ $\mathrm{CO}_{2}$ atmosphere. Excess tumor tissues not required for diagnosis were obtained from primary uveal melanoma tumors of 12 patients who were enrolled at the Xi'an No. 4 Hospital following approval by the Institutional Research Committee. The tissues were preserved at $-80^{\circ} \mathrm{C}$. Human samples were obtained after informed consent was provided by the patients, and in accordance with the Declaration of Helsinki. The present study was approved by the Ethics Committee of Xi'an No. 4 Hospital.

MTT assay. An MTT assay was employed for the evaluation of melanoma cell growth and proliferation. The experiments were carried out in 96-well plates according to the manufacturer's instructions (Roche $\mathrm{GmbH}$, Mannheim, Germany). In the MTT test, tetrazolium salts were transformed by active enzymes of the cells into intracellular formazan deposits and the cells were incubated for $4 \mathrm{~h}$ with the tetrazolium salts. After $4 \mathrm{~h}$, the purple formazan salts formed became soluble. Absorbance was determined at $490 \mathrm{~nm}$.

Migration assay. Cell migration assays were performed with a two-chamber Transwell ${ }^{\circledR}$ device (Corning, Edison, NJ, USA).
The cells were collected and suspended in RPMI-1640 medium containing $10 \%$ FCS. A Transwell apparatus with an $8-\mu \mathrm{m}$ pore size membrane (Corning) was used to analyze the migration activity. The cells were suspended in $120 \mathrm{ml}$ RPMI-1640 medium containing $0.1 \%$ FCS and then seeded in the upper chamber of the device, while $500 \mathrm{ml}$ RPMI-1640 medium containing $10 \%$ FCS was added to the lower chamber. The device was incubated at $37^{\circ} \mathrm{C}$ for $12 \mathrm{~h}$. The inner side of the upper chamber was wiped with a wet cotton swab to remove the cells, while the outer side of the chamber was gently rinsed with phosphate-buffered saline (PBS) and treated with 95\% ethanol for $30 \mathrm{~min}$. The membrane was then washed with PBS again and stained with a $0.1 \%$ crystal violet staining solution for $30 \mathrm{~min}$. After being dried, images of the membrane were taken for $>5$ fields and the cells were counted. At least three experiments were performed using the Transwell assays for each cell line.

DNA construct. The plasmids pGEM-HA-GaqQL were constructed as described in a previous study $(20,21)$. The $1.1 \mathrm{~kb}$ HindIII-NotI fragment containing the coding sequence for HA-Gaq was ligated into the blunted SalI sites of pGEM-9Zf, which was confirmed by restriction mapping and nucleotide sequencing.

Small interfering RNA transfection. Scrambled small interfering RNA (siRNA) and siRNA targeting GNAQ (sc-35429-SH) were purchased from Santa Cruz Biotechnology, Inc. (Santa Cruz, CA, USA). The cells were transfected with scrambled or GNAQ siRNA according to the manufacturer's instructions. Briefly, the scrambled and GNAQ siRNAs (30 pmol) were diluted in $500 \mu \mathrm{l}$ Dulbecco's modified Eagle's medium (DMEM) and mixed with $5 \mu$ l Lipofectamine ${ }^{\circledR}$ RNAiMAX (Invitrogen). After $15 \mathrm{~min}$ of incubation at room temperature, the complexes were added to the cells to a final volume of $3 \mathrm{ml}$ medium. The cells were then harvested at the indicated time periods for subsequent analysis. The efficiency of the GNAQ siRNA was confirmed by western blot analysis of the flag expression.

Fluorescence staining. The Mel285 cells were tranfected with blank vectors or HA-GaqQL. Following fixation with $4 \%$ formaldehyde in PBS for $10 \mathrm{~min}$, the cells were permeabilized with $0.3 \%$ Triton X-100 in PBS for $10 \mathrm{~min}$, followed by $1 \mathrm{~h}$ of blocking with $5 \%$ bovine serum albumin in PBS. The cells were stained with the primary antibody, rabbit anti-YAP, overnight at $4^{\circ} \mathrm{C}$. Fluorescence staining was performed using Alexa 488-conjugated goat anti-rabbit (green) antibody. Confocal microscopy was performed using a multiphoton Zeiss LSM 510 laser scanning microscope (Carl Zeiss, Jena, Germany). Confocal images were obtained with LSM 510 software.

Quantitative polymerase chain reaction analysis. The mRNA of uveal melanoma cells or tumor tissues was extracted with TRIzol ${ }^{\circledR}$ RNA-extraction reagent (Gibco, Rockville, MD, USA). Approximately $5 \mu \mathrm{g}$ of total RNA for each sample were reverse-transcribed into first-strand cDNA for quantitative polymerase chain reaction (RT-qPCR) analysis. RT-qPCR was performed in a final volume of $10 \mu \mathrm{l}$, containing $5 \mu \mathrm{l}$ 
Table I. Primers for quantitative real-time PCR.

\begin{tabular}{ll}
\hline Gene name & \multicolumn{1}{c}{ Sequence } \\
\hline GNAQ & 5'-CCCTAATGGCTGCTACCC-3' \\
& 5'-AAATCGTGGCCCAAACAC-3' \\
& 5'-TACTACTGCGACTGTCTTCCC-3' \\
Hes-1 & 5'-CAGCGATAACCATTAACCAA-3' \\
& 5'-AGCTCGCGGCATTCCAAG-3' \\
$\beta$-actin & 5'-AGCGGGTCACCTCGTTCA-3' \\
& 5'-CTCCATCCTGGCCTCGCTGT-3' \\
& 5'-GCTGTCACCTTCACCGTTCC-3' \\
\hline
\end{tabular}

of SsoFast ${ }^{\mathrm{TM}}$ EvaGreen ${ }^{\circledR}$ Supermix (Bio-Rad, Hercules, CA, USA), $1 \mu l$ of cDNA (1:50 dilution) and $2 \mu 1$ each of the forward and reverse primers $(1 \mathrm{mM})$. The steps in the RT-qPCR were performed as follows: $94^{\circ} \mathrm{C}$ for $2 \mathrm{~min}$ for initial denaturation; $94^{\circ} \mathrm{C}$ for $20 \mathrm{sec}, 58^{\circ} \mathrm{C}$ for $15 \mathrm{sec}$ and $72^{\circ} \mathrm{C}$ for $15 \mathrm{sec} ; 2 \mathrm{sec}$ were used for plate reading for 40 cycles; and a melt curve was generated between 65 and $95^{\circ} \mathrm{C}$. $\beta$-actin was used as a quantitative and qualitative control to normalize the gene expression. Data are analyzed using the formula: $\mathrm{R}=2^{-(\Delta \mathrm{Ct} \text { sample }-\Delta \mathrm{Ct} \text { control) }}$. The primers used in this experiment are shown in Table I.

Western blot analysis. Proteins were extracted from uveal melanoma cells and the protein concentration was quantified by the Bradford assay. A total of $20 \mu \mathrm{g}$ of protein was separated by $12 \%$ sodium dodecyl sulfate polyacrylamide gel electrophoresis and transferred to a nitrocellulose membrane (BioTeke, Beijing, China), which was incubated with $2 \%$ non-fat dry milk in Tris-buffered saline (TBS) to block non-specific binding at room temperature for $1 \mathrm{~h}$. After being blocked, the membrane was incubated in blocking buffer containing primary antibodies overnight at $4^{\circ} \mathrm{C}$. Antibodies including anti-Jag-1, anti-NICD, anti-Hes- 1 and anti- $\beta$ actin were purchased from Santa Cruz Biotechnology, Inc. Subsequently, the membrane was washed with TBS-Tween for $10 \mathrm{~min}$ and incubated with horseradish peroxidase-conjugated secondary antibody (Tiangen Corporation, Beijing, China) diluted in blocking buffer for $1 \mathrm{~h}$ at room temperature. After being washed again with TBS-Tween buffer for $10 \mathrm{~min}$, proteins were detected using enhanced chemiluminescence (Pierce, Rockford, IL, USA).

Statistical analysis. The statistical significance of differences was assessed using SPSS 15.0 (SPSS Science, Chicago, IL, USA). Differences between the two groups were analyzed by the Student's t-test. Correlations were assessed using the Spearman's rank correlation coefficient. Differences between multiple groups were analyzed by the ANOVA. $\mathrm{P}<0.05$ was considered to indicate a statistically significant result.

\section{Results}

Oncogene GNAQ contributes to uveal melanoma cell viability and migration. Mutant GNAQ has been identified in certain uveal melanoma cell lines including 92.1, OMM2.2 and
OMM2.5 (22). To determine the effect of GNAQ on uveal melanoma cells, the cultured 92.1, OMM2.2 and OMM2.5 cells were transfected with scrambled or GNAQ siRNA. Transfection of GNAQ siRNA resulted in a 67,70 and $74 \%$ inhibition of GNAQ mRNA expression in 92.1, OMM2.2 and OMM2.5 cells, respectively (Fig. 1A). The viability of these transfected cells was evaluated by MTT over 24-96 h. The results showed that GNAQ knockdown significantly inhibited the viability of 92.1, OMM2.2 and OMM2.5 cells (Fig. 1B-D). GNAQ knockdown also reduced the migratory rates of 92.1, OMM2.2 and OMM2.5 cells compared with the respective controls (Fig. 1E). Moreover, cells such as Mel285 and Mel290 were absent from the mutant GNAQ. Therefore, we examined the effect of the GNAQ expression on these cells through transfection with human influenza hemagglutinin A epitope (HA)-tagged G $\alpha q Q L$. Consequently, HA-G $\alpha q Q L$ transfection resulted in a significant increase in the GNAQ mRNA expression (Fig. 1F), and increased the viability and migration of the Mel285 and Mel290 cells (Fig. 1G-I). These results indicated that mutant GNAQ may promote uveal melanoma cell viability and migration.

GNAQ activates Notch signaling in uveal melanoma cells. Activation of Notch signaling is involved in the carcinogenesis of various tissues including ocular tissues (23-25). As mutant GNAQ was highly expressed in uveal melanoma cells (26), we hypothesized that GNAQ causes Notch signal activation and contributed to cell growth and migration. To validate our hypothesis, GNAQ expression in 92.1 cells was knocked down by GNAQ siRNA, and the expression of Jag-1 (Notch ligand), NICD and Hes-1 (Notch target gene) was analyzed by western blotting. A decreased expression of Jag-1, NCID and Hes-1 was observed in the GNAQ knockdown cells (Fig. 2A). Furthermore, HA-GaqQL transfection in the Mel285 cells notably upregulated the expression of Jag-1, NCID and Hes-1 (Fig. 2B). These results revealed that the Notch signaling may be triggered by mutant GNAQ in uveal melanoma cells.

Inhibition of Notch signaling blocks uveal melanoma cell viability and migration induced by GNAQ. To confirm the effect of Notch activation induced by GNAQ on uveal melanoma cells, the Mel285 cells were transfected with HA-GaqQL and treated with or without $5 \mu \mathrm{mol} / 1 \mathrm{MRK003}$ (a potent $\gamma$-secretase inhibitor). Compared with the HA-GaqQL transfection group, treatment with MRK003 significantly inhibited cell viability and migration (Fig. 3A and B). Furthermore, Hes-1 expression in these cells was decreased by MRK003 (Fig. 3C). These results indicated that inactive Notch impeded the effect of GNAQ on uveal melanoma cells.

YAP mediates GNAQ-induced Notch activation. It has been shown that nuclear YAP induces Notch activation (27). Therefore, we investigated whether YAP is involved in GNAQ-induced Notch activation. Mel285 cells were transfected with HA-GaqQL, and the YAP phosphorylation levels and nuclear translocation were detected. Compared with the Mel285 cells transfected with empty vectors, those transfected with HA-GaqQL showed decreased YAP phosphorylation (Fig. 4A) and increased YAP nuclear translocation (Fig. 4B). Furthermore, YAP expression in the 92.1 cells 
A

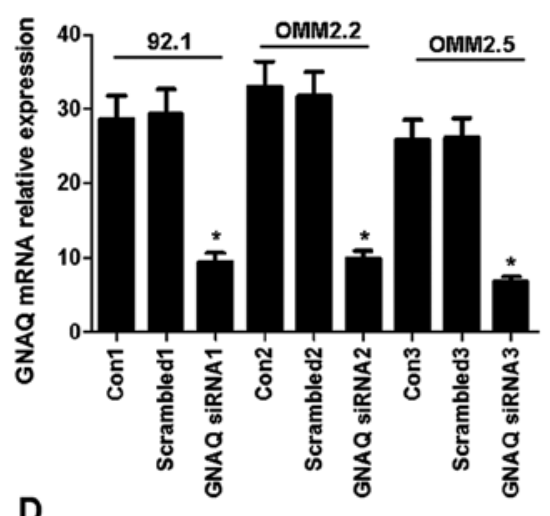

D

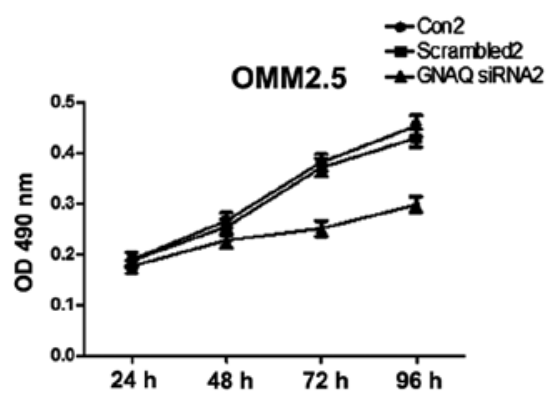

G

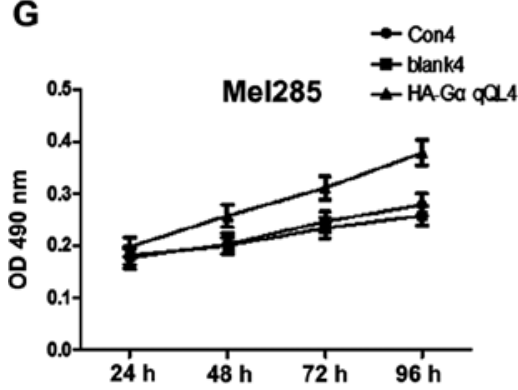

B

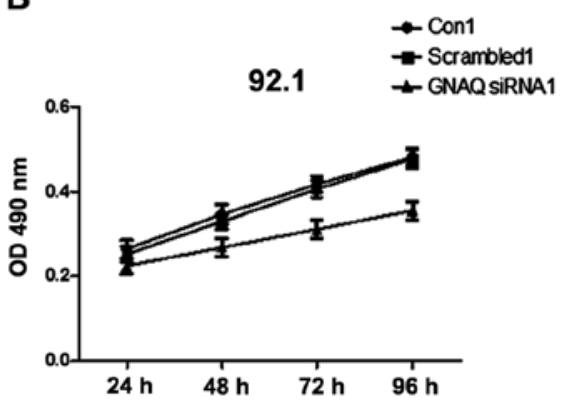

E

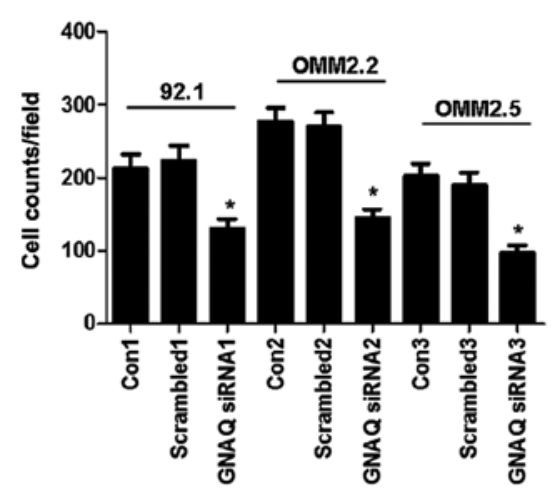

H

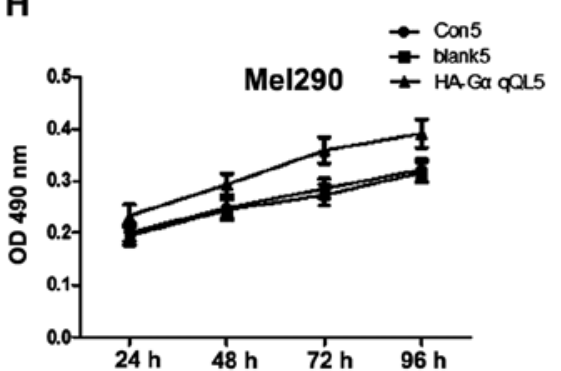

C

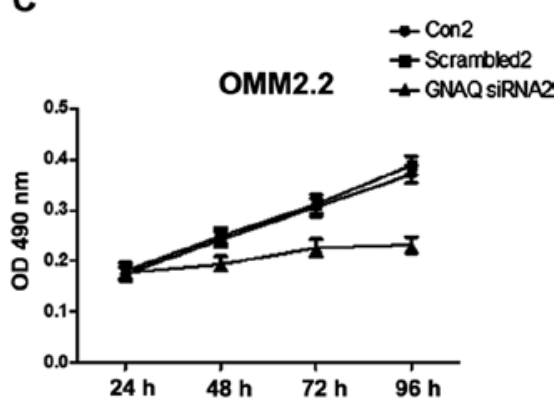

F

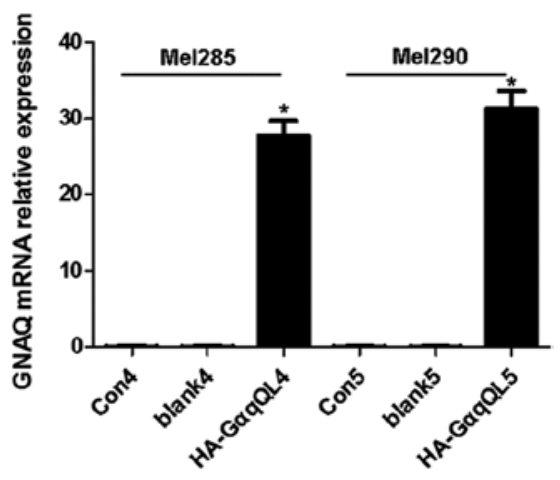

I

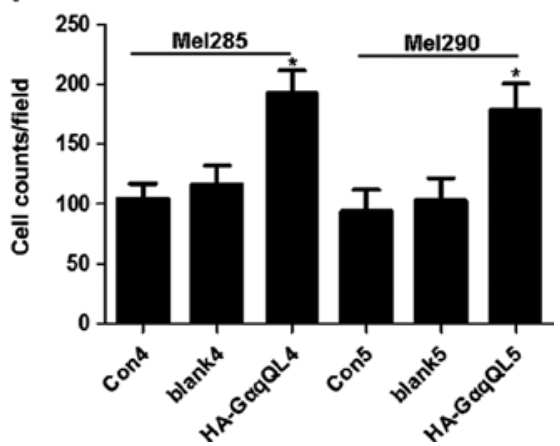

Figure 1. Evaluation of the viability and migration of uveal melanoma cells following transfection with GNAQ siRNA or human influenza hemagglutinin A epitope (HA)-tagged GaqQL. (A) Analysis of the GNAQ mRNA expression in the 92.1, OMM2.2 and OMM2.5 cells by RT-qPCR. Determination of cell viability of the (B) 92.1, (C) OMM2.2 and (D) OMM2.5 cells by MTT following transfection with GNAQ siRNA. (E) Evaluation of cell migration of the 92.1, OMM2.2 and OMM2.5 cells by the Transwell ${ }^{\circledR}$ assay following transfection with GNAQ siRNA. (F) Analysis of the GNAQ mRNA expression in the Mel285 and Mel290 cells by RT-qPCR. Determination of cell viability of the (G) Mel285 and (H) Mel290 cells by MTT following HA-GaqQL transfection. (I) Evaluation of cell migration of the Mel285 and Mel290 cells by the Transwell assay following HA-GaqQL transfection. ${ }^{*} \mathrm{P}<0.05$ vs. Con1, Con2, Con3, Con4 or Con5.
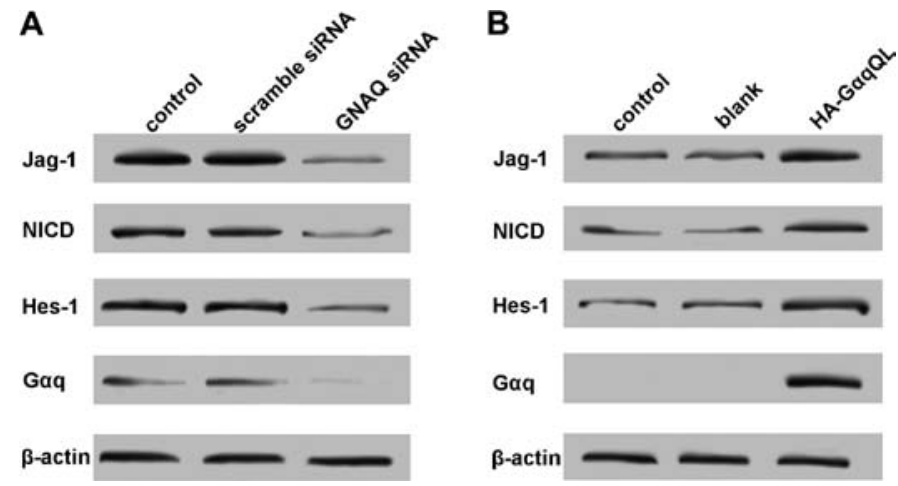

Figure 2. Analysis of the Jag-1, NCID and Hes-1 protein expression by western blotting. (A) Analysis of the Jag-1, NCID and Hes-1 protein expression in the 92.1 cells following transfection with GNAQ siRNA. (B) Analysis of the Jag-1, NCID and Hes-1 protein expression in the Mel285 cells following HA-GaqQL transfection. 

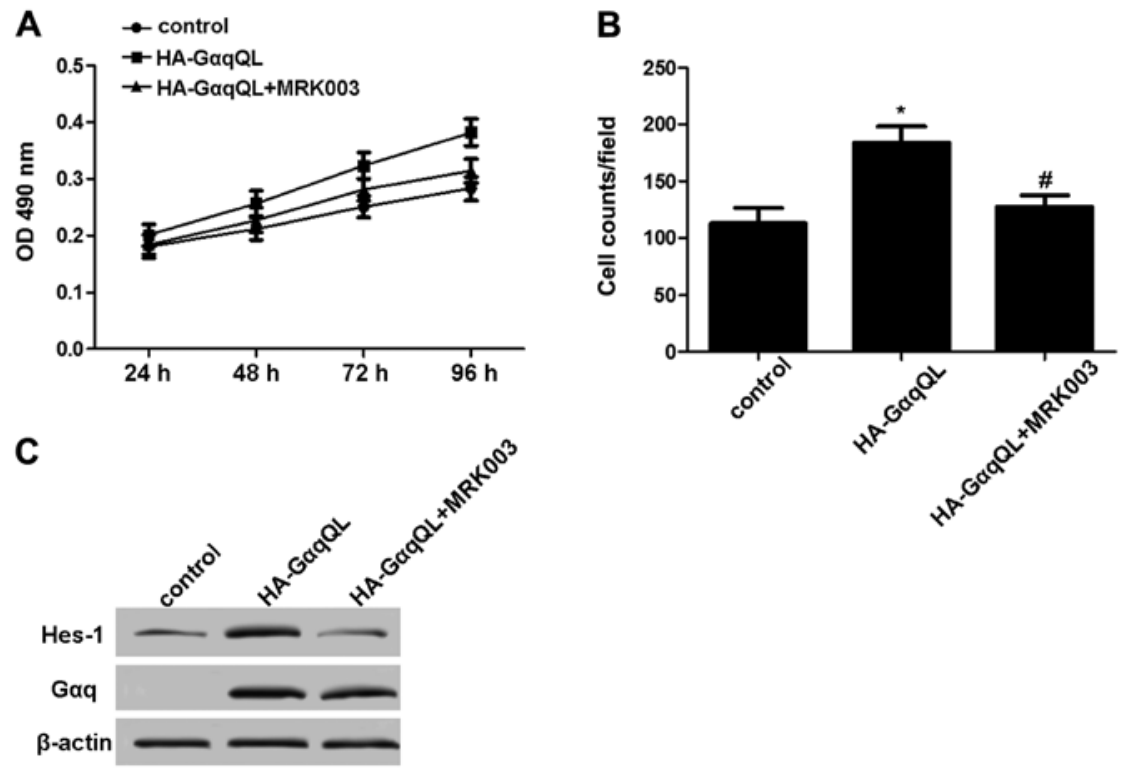

Figure 3. Evaluation of the viability and migration of uveal melanoma cells. (A) Evaluation of cell viability of the Mel285 cells following HA-GaqQL transfection and treatment with or without MRK003. (B) Evaluation of cell migration of the Mel285 cells following HA-GaqQL transfection and treatment with or without MRK003. (C) Analysis of Hes-1 protein expression following HA-GaqQL transfection and treatment with or without MRK003. ${ }^{*}<0.05$ vs. control, ${ }^{\#} \mathrm{P}<0.05$ vs. HA-GaqQL.

A

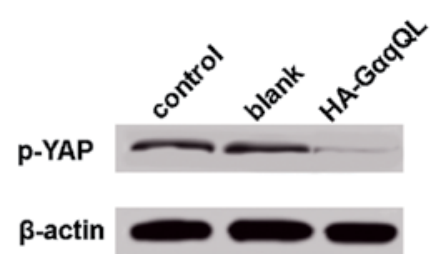

B

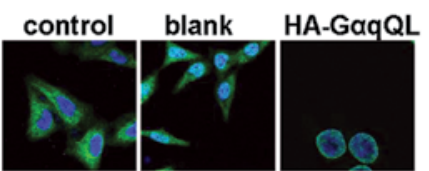

D

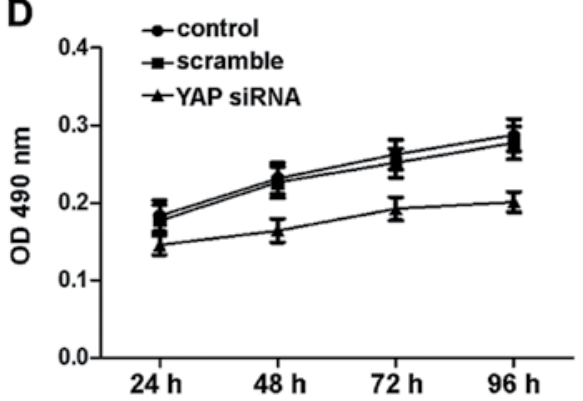

C

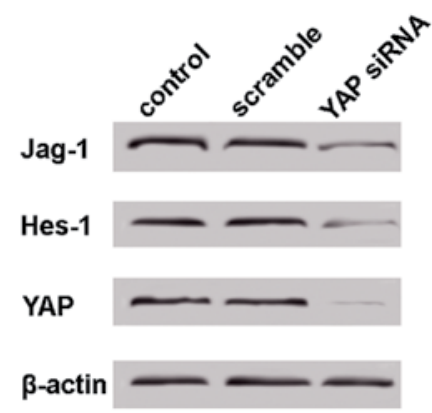

E

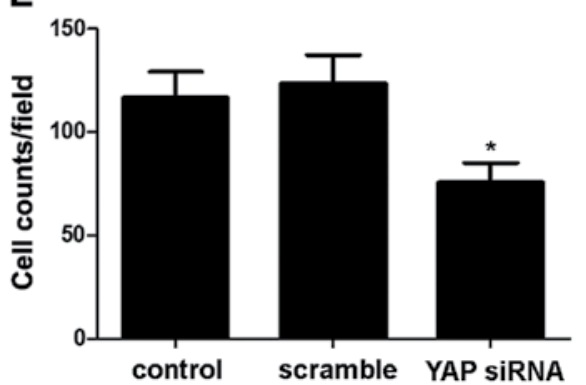

Figure 4. Exploration of the role of YAP in uveal melanoma cells. (A) Analysis of YAP phosphorylation by western blotting in the Mel285 cells after HA-GaqQL transfection. (B) Detection of YAP nuclear translocation (green) by fluorescent staining. (C) Western blot analysis of the Jag-1 and Hes-1 protein expression in the 92.1 cells after transfection with YAP siRNA. (D) Determination of cell viability of the 92.1 cells after transfection with YAP siRNA. (E) Evaluation of cell migration of the 92.1 cells after transfection with YAP siRNA. $\mathrm{P}<0.05$ vs. control. YAP, Yes-associated protein.

was inhibited, and Jag-1 and Hes-1 expression was reduced by YAP siRNA (Fig. 4C). Additionally, the viability and migration of the 92.1 cells was inhibited by the YAP siRNA transfection (Fig. 4D and E). These results demonstrated that GNAQ inhibits YAP phosphorylation and promotes YAP translocation, which mediated Notch activation in uveal melanoma cells.
GNAQ contributes to the oncogenic activation of Notch in human uveal melanoma. To confirm the connection between the GNAQ, YAP and Notch signaling in human uveal melanoma, total RNA was isolated from 12 fresh-frozen human uveal melanoma samples, and the mRNA levels of GNAQ, YAP, Jag-1 and Hes-1 were analyzed. Positive correlations between the GNAQ and Jag-1 mRNA levels and between the 

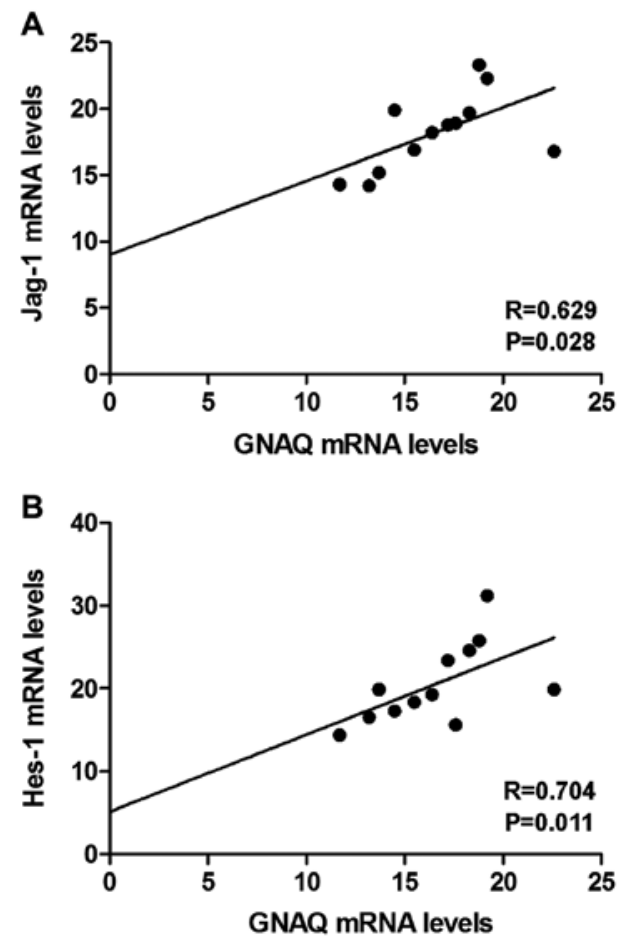

Figure 5. Analysis of correlations between the mRNA levels by Spearman's rank correlation coefficient. Analysis of correlations between the (A) GNAQ and Jag-1 and (B) GNAQ and Hes-1 mRNA levels.

GNAQ and Hes-1 mRNA levels were observed (Fig. 5A and B). However, no correlation was found between the GNAQ and YAP mRNA levels, which suggested that GNAQ regulated YAP protein phosphorylation but not its transcript level.

\section{Discussion}

A high incidence of mutations in $\mathrm{G}$ protein-coupled receptors and $G$ proteins has been observed in melanomas $(8,28,29)$. Notably, GNAQ and GNA11 mutations have been reported in the majority of uveal melanomas, $83 \%$ of blue nevi, $6 \%$ of cutaneous melanomas and 59\% of tumors occurring in the meninges $(30,31)$. The potential role of GTPase-deficient mutants of several $\mathrm{G} \alpha$ subunits in carcinogenesis has been previously demonstrated $(32,33)$. The $\mathrm{GNAQ}^{\mathrm{Q} 209 \mathrm{~L}}$ mutation contributes to a loss of GTPase activity and constitutive activation of GNAQ $(34,35)$. Subsequently, dissociation of GNAQ in its GTP-bound state results, via Ras and Raf signaling, in MEK1/ERK activation, which ultimately modulates cell growth and migration (36). Van Raamsdonk et al (31) found that blocking the GNAQ expression in OMM1.3 cells resulted in a significant decrease in the cell number, loss of anchorage-independent growth and a marked increase in the sub-G0/G1 population. The present study confirmed that GNAQ mutation was critical for the viability and migration of melanoma cells.

Notch activation has been found to be involved in the viability of cutaneous melanoma. The elevated expression of the Notch pathway members has been described in melanoma cells compared with normal melanocytes, and treatment with the tripeptide GSI caused apoptosis in melanoma cells $(37,38)$. In a study by Asnaghi et al (39), Jag-2 was introduced into the
Mel285 and Mel290 cells, and these cells showed enhanced cell growth and motility as evaluated by the wound-healing and Transwell invasion assays. By contrast, transfection of 92.1 and OMM1 cells with Jag-2 short hairpin RNAs indicated that knockdown of the ligand significantly inhibited cell growth, invasion and migration. Huang et al (40) reported that knockdown of Notch1 in uveal melanoma cells with siRNA resulted in significant cell growth inhibition as well as enhanced apoptosis and cell cycle arrest in vitro. Treatment with siNotch1 in vivo also significantly inhibited tumor growth and prolonged the mouse survival rate in a OCM1 xenograft model. Furthermore, in primary uveal melanoma tissues and uveal melanoma cells, MRK003 treatment inhibited anchorage-independent cell growth and invasion, and reduced phosphorylation levels of STAT3 and ERK1/2 (18). In the present study, we demonstrated that mutant GNAQ contributed to the activation of Notch signaling, and inhibition of Notch signaling impeded the stimulatory effect of GNAQ on melanoma cell viability and migration.

It has been established that YAP may be involved in the modulation of tumor cell growth and invasion. Overexpressed YAP in human hepatocellular carcinoma cell lines and mouse hepatocytes upregulated Jag-1, resulting in Notch signaling activation and proliferation promotion (27). Zhou et al (41) demonstrated that YAP was overexpressed in human colon cancers and colon cancer-derived cell lines, where YAP depletion strongly reduces $\beta$-catenin and Notch signaling, and inhibits proliferation and the survival rate. Notably, YAP has been reported to be regulated by mutant GNAQ. Feng et al demonstrated that GNAQ stimulates YAP dephosphorylation and translocation through a Trio-Rho/Rac signaling circuitry promoting actin polymerization and the YAP-dependent growth of uveal melanoma cells (42). Moreover, in cell culture and human tumors, cancer-associated $\mathrm{Gq} / 11$ mutants were demonstrated to activate YAP, which mediated the oncogenic activity of mutant $\mathrm{Gq} / 11$ in uveal melanoma development (22). The present findings have demonstrated that YAP dephosphorylation and nuclear translocation may play a key role in Notch activation and cell viability and migration induced by GNAQ. Additionally, the present study provided evidence that positive correlations between the GNAQ and Jag-1 mRNA levels and between the GNAQ and Hes-1 mRNA levels were constant in human uveal melanomas.

In conclusion, results of the present study have shown the critical role of mutant GNAQ in melanoma cell viability and migration through the activation of Notch signaling. Of note, YAP dephosphorylation and nuclear translocation were found to be essential for the interaction between GNAQ and Notch signaling. Thus, the present study identified a critical target for uveal melanoma treatment.

\section{References}

1. Bedikian AY: Metastatic uveal melanoma therapy: Current options. Int Ophthalmol Clin 46: 151-166, 2006.

2. Biswas J, Krishnakumar S and Shanmugam MP: Uveal melanoma in Asian Indians: A clinicopathological study. Arch Ophthalmol 120: 522-523, 2002.

3. Sakamoto T, Sakamoto M, Yoshikawa H, Hata Y, Ishibashi T, Ohnishi $\mathrm{Y}$ and Inomata $\mathrm{H}$ : Histologic findings and prognosis of uveal malignant melanoma in Japanese patients. Am J Ophthalmol 121: 276-283, 1996. 
4. Kuo PK, Puliafito CA, Wang KM, Liu HS and Wu BF: Uveal melanoma in China. Int Ophthalmol Clin 22: 57-71, 1982.

5. Singh AD, Turell ME and Topham AK: Uveal melanoma: Trends in incidence, treatment, and survival. Ophthalmology 118: 1881-1885, 2011.

6. Collaborative Ocular Melanoma Study Group: Assessment of metastatic disease status at death in 435 patients with large choroidal melanoma in the Collaborative Ocular Melanoma Study (COMS): COMS report no. 15. Arch Ophthalmol 119: 670-676, 2001

7. Gragoudas ES, Egan KM, Seddon JM, Glynn RJ, Walsh SM, Finn SM, Munzenrider JE and Spar MD: Survival of patients with metastases from uveal melanoma. Ophthalmology 98 383-390, 1991.

8. O'Hayre M, Vázquez-Prado J, Kufareva I, Stawiski EW, Handel TM, Seshagiri S and Gutkind JS: The emerging mutational landscape of $\mathrm{G}$ proteins and $\mathrm{G}$-protein-coupled receptors in cancer. Nat Rev Cancer 13: 412-424, 2013.

9. Daniels AB, Lee JE, MacConaill LE, Palescandolo E, Van Hummelen P, Adams SM, DeAngelis MM, Hahn WC, Gragoudas ES, Harbour JW, et al: High throughput mass spectrometry-based mutation profiling of primary uveal melanoma Invest Ophthalmol Vis Sci 53: 6991-6996, 2012.

10. Ambrosini G, Pratilas CA, Qin LX, Tadi M, Surriga O, Carvajal RD and Schwartz GK: Identification of unique MEK-dependent genes in GNAQ mutant uveal melanoma involved in cell growth, tumor cell invasion, and MEK resistance. Clin Cancer Res 18: 3552-3561, 2012.

11. Van Raamsdonk CD, Griewank KG, Crosby MB, Garrido MC, Vemula S, Wiesner T, Obenauf AC, Wackernagel W, Green G, Bouvier N, et al: Mutations in GNA11 in uveal melanoma. N Engl J Med 363: 2191-2199, 2010.

12. Mumm JS and Kopan R: Notch signaling: From the outside in Dev Biol 228: 151-165, 2000

13. Brou C, Logeat F, Gupta N, Bessia C, LeBail O, Doedens JR, Cumano A, Roux P, Black RA and Israël A: A novel proteolytic cleavage involved in Notch signaling: The role of the disintegrinmetalloprotease TACE. Mol Cell 5: 207-216, 2000.

14. Borggrefe $\mathrm{T}$ and Oswald $\mathrm{F}$ : The Notch signaling pathway: Transcriptional regulation at Notch target genes. Cell Mol Life Sci 66: 1631-1646, 2009.

15. Jarriault S, Le Bail O, Hirsinger E, Pourquié O, Logeat F, Strong CF, Brou C, Seidah NG and Isra 1 A: Delta-1 activation of notch-1 signaling results in $H E S-1$ transactivation. Mol Cell Biol 18: 7423-7431, 1998

16. Liu ZJ, Xiao M, Balint K, Smalley KS, Brafford P, Qiu R, Pinnix CC, $\mathrm{Li} \mathrm{X}$ and Herlyn M: Notch1 signaling promotes primary melanoma progression by activating mitogen-activated protein kinase/phosphatidylinositol 3-kinase-Akt pathways and up-regulating N-cadherin expression. Cancer Res 66: 4182-4190, 2006.

17. Pinnix CC, Lee JT, Liu ZJ, McDaid R, Balint K, Beverly LJ, Brafford PA, Xiao M, Himes B, Zabierowski SE, et al: Active Notch1 confers a transformed phenotype to primary human melanocytes. Cancer Res 69: 5312-5320, 2009.

18. Asnaghi L, Ebrahimi KB, Schreck KC, Bar EE, Coonfield ML, Bell WR, Handa J, Merbs SL, Harbour JW and Eberhart CG: Notch signaling promotes growth and invasion in uveal melanoma. Clin Cancer Res 18: 654-665, 2012.

19. Babchia N, Calipel A, Mouriaux F, Faussat AM and Mascarelli F: The PI3K/Akt and mTOR/P70S6K signaling pathways in human uveal melanoma cells: Interaction with B-Raf/ERK. Invest Ophthalmol Vis Sci 51: 421-429, 2010.

20. Mende U, Kagen A, Cohen A, Aramburu J, Schoen FJ and Neer EJ: Transient cardiac expression of constitutively active $\mathrm{G} \alpha$ leads to hypertrophy and dilated cardiomyopathy by calcineurin-dependent and independent pathways. Proc Natl Acad Sci USA 95: 13893-13898, 1998

21. Marinissen MJ, Servitja JM, Offermanns S, Simon MI and Gutkind JS: Thrombin protease-activated receptor-1 signals through $\mathrm{G}_{\mathrm{q}}$ - and $\mathrm{G}_{13}$-initiated MAPK cascades regulating c-Jun expression to induce cell transformation. J Biol Chem 278 : 46814-46825, 2003

22. Yu FX, Luo J, Mo JS, Liu G, Kim YC, Meng Z,Zhao L, Peyman G, Ouyang $\mathrm{H}$, Jiang W, et al: Mutant Gq/11 promote uveal melanoma tumorigenesis by activating YAP. Cancer Cell 25: 822-830, 2014

23. Cheng P, Kumar V, Liu H, Youn JI, Fishman M, Sherman S and Gabrilovich D: Effects of notch signaling on regulation of myeloid cell differentiation in cancer. Cancer Res 74: 141-152, 2014.
24. Neradugomma NK, Subramaniam D, Tawfik OW, Goffin V, Kumar TR, Jensen RA and Anant S: Prolactin signaling enhances colon cancer stemness by modulating Notch signaling in a Jak2STAT3/ERK manner. Carcinogenesis 35: 795-806, 2014.

25. Xie M, He CS, Wei SH and Zhang L: Notch-1 contributes to epidermal growth factor receptor tyrosine kinase inhibitor acquired resistance in non-small cell lung cancer in vitro and in vivo. Eur J Cancer 49: 3559-3572, 2013.

26. Lamba S, Felicioni L, Buttitta F, Bleeker FE, Malatesta S, Corbo V, Scarpa A, Rodolfo M, Knowles M, Frattini M, et al: Mutational profile of $G N A Q^{\mathrm{Q} 209}$ in human tumors. PLoS One 4: e6833, 2009.

27. Tschaharganeh DF, Chen X, Latzko P, Malz M, Gaida MM, Felix K, Ladu S, Singer S, Pinna F, Gretz N, et al: Yes-associated protein up-regulates Jagged-1 and activates the Notch pathway in human hepatocellular carcinoma. Gastroenterology 144: 1530-1542.e12, 2013.

28. Kan Z, Jaiswal BS, Stinson J, Janakiraman V, Bhatt D, Stern HM, Yue P, Haverty PM, Bourgon R, Zheng J, et al: Diverse somatic mutation patterns and pathway alterations in human cancers. Nature 466: 869-873, 2010.

29. Prickett TD, Wei X, Cardenas-Navia I, Teer JK, Lin JC, Walia V, Gartner J, Jiang J, Cherukuri PF, Molinolo A, et al: Exon capture analysis of $\mathrm{G}$ protein-coupled receptors identifies activating mutations in GRM3 in melanoma. Nat Genet 43: 1119-1126, 2011.

30. Küsters-Vandevelde HV, Klaasen A, Küsters B, Groenen PJ, van Engen-van Grunsven IA, van Dijk MR, Reifenberger G, Wesseling P and Blokx WA: Activating mutations of the GNAQ gene: A frequent event in primary melanocytic neoplasms of the central nervous system. Acta Neuropathol 119: 317-323, 2010.

31. Van Raamsdonk CD, Bezrookove V, Green G, Bauer J, Gaugler L, O'Brien JM, Simpson EM, Barsh GS and Bastian BC: Frequent somatic mutations of GNAQ in uveal melanoma and blue naevi. Nature 457: 599-602, 2009.

32. Vallar L, Spada A and Giannattasio G: Altered $\mathrm{G}_{\mathrm{s}}$ and adenylate cyclase activity in human $\mathrm{GH}$-secreting pituitary adenomas. Nature 330: 566-568, 1987.

33. Lyons J, Landis CA, Harsh G, Vallar L, Grünewald K, Feichtinger H, Duh QY, Clark OH, Kawasaki E, Bourne HR, et al: Two $\mathrm{G}$ protein oncogenes in human endocrine tumors. Science 249: 655-659, 1990.

34. Van Raamsdonk CD, Fitch KR, Fuchs H, de Angelis MH and Barsh GS: Effects of G-protein mutations on skin color. Nat Genet 36: 961-968, 2004

35. Markby DW, Onrust R and Bourne HR: Separate GTP binding and GTPase activating domains of a $\mathrm{G}$ alpha subunit. Science 262 : 1895-1901, 1993

36. McCubrey JA, Steelman LS, Chappell WH, Abrams SL, Wong EW, Chang F, Lehmann B, Terrian DM, Milella M, Tafuri A, et al: Roles of the Raf/MEK/ERK pathway in cell growth, malignant transformation and drug resistance. Biochim Biophys Acta 1773: 1263-1284, 2007.

37. Hoek K, Rimm DL, Williams KR, Zhao H, Ariyan S, Lin A, Kluger HM, Berger AJ, Cheng E, Trombetta ES, et al: Expression profiling reveals novel pathways in the transformation of melanocytes to melanomas. Cancer Res 64: 5270-5282, 2004.

38. Qin JZ, Stennett L, Bacon P, Bodner B, Hendrix MJ, Seftor RE, Seftor EA, Margaryan NV, Pollock PM, Curtis A, et al: p53-independent NOXA induction overcomes apoptotic resistance of malignant melanomas. Mol Cancer Ther 3: 895-902, 2004.

39. Asnaghi L, Handa JT, Merbs SL, Harbour JW and Eberhart CG: A role for Jag2 in promoting uveal melanoma dissemination and growth. Invest Ophthalmol Vis Sci 54: 295-306, 2013.

40. Huang X, Wang L, Zhang H, Wang H, Zhao X, Qian G, Hu J, Ge S and Fan X: Therapeutic efficacy by targeting correction of Notch1-induced aberrants in uveal tumors. PLoS One 7: e44301, 2012.

41. Zhou D, Zhang Y, Wu H, Barry E, Yin Y, Lawrence E, Dawson D, Willis JE, Markowitz SD, Camargo FD, et al: Mst1 and Mst2 protein kinases restrain intestinal stem cell proliferation and colonic tumorigenesis by inhibition of Yes-associated protein (Yap) overabundance. Proc Natl Acad Sci USA 108: E1312-E1320, 2011.

42. Feng X, Degese MS, Iglesias-Bartolome R, Vaque JP, Molinolo AA, Rodrigues M, Zaidi MR, Ksander BR, Merlino G, Sodhi A, et al: Hippo-independent activation of YAP by the GNAQ uveal melanoma oncogene through a trio-regulated rho GTPase signaling circuitry. Cancer Cell 25: 831-845, 2014. 